\title{
BMJ Open Multimorbidity in a marginalised, street-health Australian population: a retrospective cohort study
}

\author{
Tom Brett, ${ }^{1}$ Diane E Arnold-Reed, ${ }^{1,2}$ Lakkhina Troeung, ${ }^{1}$ Max K Bulsara, ${ }^{3}$ \\ Annalisse Williams, ${ }^{4}$ Robert G Moorhead ${ }^{5}$
}

To cite: Brett T, ArnoldReed DE, Troeung $\mathrm{L}$, et al. Multimorbidity in a marginalised, street-health Australian population: a retrospective cohort study. BMJ Open 2014:4:e005461. doi:10.1136/bmjopen-2014005461

- Prepublication history for this paper is available online. To view these files please visit the journal online (http://dx.doi.org/10.1136/ bmjopen-2014-005461).

Received 14 April 2014 Revised 27 June 2014 Accepted 3 July 2014

CrossMark

For numbered affiliations see end of article.

Correspondence to Professor Tom Brett; tom.brett@nd.edu.au

\begin{abstract}
Objectives: Demographic and presentation profile of patients using an innovative mobile outreach clinic compared with mainstream practice.

Design: Retrospective cohort study.

Setting: Primary care mobile street health clinic and mainstream practice in Western Australia.
\end{abstract}

Participants: 2587 street health and 4583 mainstream patients.

Main outcome measures: Prevalence and patterns of chronic diseases in anatomical domains across the entire age spectrum of patients and disease severity burden using Cumulative IIIness Rating Scale (CIRS).

Results: Multimorbidity (2+ CIRS domains) prevalence was significantly higher in the street health cohort $(46.3 \%, 1199 / 2587)$ than age-sex-adjusted mainstream estimate $(43.1 \%, 2000 / 4583), p=0.011$. Multimorbidity prevalence was significantly higher in street health patients $<45$ years $(37.7 \%, 615 / 1649)$ compared with age-sex-adjusted mainstream patients (33\%, 977/ 2961), $p=0.003$ but significantly lower if $65+$ years $(62 \%, 114 / 184$ vs $90.7 \%, 322 / 355, p<0.001)$. Controlling for age and gender, the mean CIRS Severity Index score for street health $(\mathrm{M}=1.4, \mathrm{SD}=0.91)$ was significantly higher than for mainstream patients $(M=1.1, S D=0.80), p<0.001$. Furthermore, $44.2 \%$ (530/ $1199)$ of street health patients had at least one level 3 or 4 score across domains compared with $18.3 \%$ (420/ $2294)$ for mainstream patients, $p<0.001$. Street health population comprised $29.6 \%$ (766/2587) Aboriginal patients with $50.4 \%$ (386/766) having multimorbidity compared with $44.6 \%$ (813/1821) for non-Aboriginals, $\mathrm{p}=0.007$. There were no comprehensive data on Indigenous status in the mainstream cohort available for comparison. Musculoskeletal, respiratory and psychiatric domains were most commonly affected with multimorbidity significantly associated with male gender, increasing age and Indigenous status.

Conclusions: Age-sex-adjusted multimorbidity prevalence and disease severity is higher in the street health cohort. Earlier onset (23-34 years)

multimorbidity is found in the street health cohort but prevalence is lower in 65+ years than in mainstream patients. Multimorbidity prevalence is higher for Aboriginal patients of all ages.

\section{Strengths and limitations of this study}

New information on a vulnerable, street-based population accessing an accredited, mobile outreach medical service.

- The large cohort size $(n=2587)$ involving a total street-based population seen over a 6-year period compared with 4583 mainstream patients from a similar catchment area.

- Includes a severity rating for each patient in addition to prevalence and patterns of chronic diseases recorded.

- The open access policy to the street health service could have diluted the proportion of more traditional users of the service because of one-off opportunistic and convenience attendances.

- The street health population is based on attendances over a 6-year period while the comparator mainstream practice data are based on attendances over 6 months.

\section{INTRODUCTION}

The combination of multiple chronic diseases (multimorbidity) and poor access to primary healthcare results in serious social, economic and health consequences ${ }^{1-5}$ as well as providing considerable challenges for service providers. Marginalised and homeless people have more chronic diseases, high mortality rates, high direct and indirect healthcare $\operatorname{costs}^{6}{ }^{7}$ and poor utilisation of primary care health services than the general population. ${ }^{1}{ }^{8-11}$ Alcohol and drug-related deaths, smoking-related diseases, ischaemic heart disease and respiratory diseases are especially common. ${ }^{9}$ A systematic review ${ }^{12}$ found homeless people in Western countries had much greater drug and alcohol dependence compared with age-matched populations while psychotic illnesses and personality disorders were also more common. Canadian homeless and marginally housed people 
have $32 \%$ probability of survival to 75 years among men and $60 \%$ among women with housing a key marker for socioeconomic disadvantage. ${ }^{9}$ Death rates among 'rough sleepers' in the UK are 25 times that of the housed population. ${ }^{13}$

Risk factors influencing access to health services include lack of suitable housing, ${ }^{9}{ }^{14}$ mental health problems, ${ }^{12}{ }^{15}$ poor education, unemployment and lack of regular income. ${ }^{16}{ }^{17}$ Social marginalisation impacts negatively on healthcare utilisation including fear of stigmatisation on visiting mainstream practices and waiting rooms. ${ }^{18}$ People from Indigenous, non-English speaking and refugee backgrounds often avoid contact with a regular doctor and only seek help when a crisis develops. ${ }^{19-21}$ Such individuals have poorer health outcomes, ${ }^{22}$ exhibiting patterns of chronic, multimorbid disease at a younger age compared with the general population. ${ }^{23}$ In Scotland, Mercer and Watt ${ }^{3}$ found an increased burden of ill health and multimorbidity in deprived areas, resulting in greater demands on primary healthcare leading to reduced access, less patientdoctor time and more general practitioner (GP) stress but less patient enablement.

The 'Freo Street Doctor' is an accredited, street-based mobile health clinic established in 2005 to help meet the needs of marginalised and homeless patients unable or unwilling to access mainstream primary healthcare. It operates from a number of designated areas within Fremantle and surrounding suburbs in Western Australia. While the target population is mainly marginalised and disadvantaged patients, access to the service is unrestricted with electronic records kept for all attendees. The clinic team consists of GPs, nurses, outreach workers, Indigenous health workers and social workers. Our study aims to examine the demographic profile of patients using this street health service compared with mainstream primary care practices, the range and severity of morbidities/chronic diseases across anatomical domains and compares these parameters for Aboriginal and non-Aboriginal patients.

\section{METHODS}

\section{Study setting}

The entire patient cohort attending the 'Freo Street Doctor' service over the period 1 January 2006 to 31 December 2011 was examined. Patient data were entered by reception, medical and nursing staff into standard practice software and stored centrally at Fremantle Medicare Local offices. Data for the study were extracted from the central medical records and compared with the total patient population attending a mainstream general practice clinic $^{2}$ servicing the same catchment area over the period 1 July to 31 December 2008.

\section{Data extraction}

Data extraction was undertaken by two GPs and two medical students, all with similar training and prior experience in the use and application of the Cumulative Illness Rating Scale (CIRS). The scoring of chronic conditions using the validated CIRS has been described in detail previously ${ }^{20} 25$ as has the Severity Index (SI) classification. ${ }^{24}$

Briefly, records were reviewed and 42 conditions were scored according to CIRS guidelines: $0=$ no problems, $1=$ mild problems, $2=$ moderate morbidity, $3=$ =severe chronic problems, $4=$ extremely severe functional impairment. Conditions were categorised into 14 anatomical domains. Maximum scores for each domain were added to yield a total score ranging from 0 to 56 for each patient. The total score was then divided by the number of domains with morbidities to generate a CIRS score for each patient ranging from 0 to 4 . Severity ratings were defined as $0=$ none $/$ low, $1=$ mild, $2=$ moderate and $3 / 4=$ severe.

For both cohorts conditions within a particular anatomical domain were noted to be present only if the information in the records suggested the condition was ongoing/ chronic and then rated according to the CIRS. The street health data set contained a large number of one-off consultations. Some attendees had no fixed abode with many using drop-in centres as proxy addresses.

As far as possible, data extractors took precautions to guard against double counting. There may have been some limited cross-over between street and mainstream practices but, in general, patients attending one service tended to continue doing so.

\section{Operational definition}

Our operational definition of multimorbidity was the co-occurrence of conditions across two or more (2+) domains in individual patients. ${ }^{26}$ After data extraction was completed, a random sample of 30 patients across the entire age spectrum for both clinics was reassessed to measure consistency among raters.

\section{Data analysis}

Data analysis was conducted using SPSS V.22 (IBM Corporation). All statistical analyses were tested against an $\alpha$ level of 0.05 (two-tailed).

Sample characteristics are expressed as means (SD of the mean) for continuous variables and as frequencies (percentages) for categorical variables. Independent sample $\mathrm{t}$ tests and $\chi^{2}$ tests were used to examine any demographic differences between the two samples.

The crude prevalence of multimorbidity was calculated as the number of patients with long-term conditions in 2+ morbidity domains as a proportion of the total sample. Given significant differences in age-sex distribution between the two samples, age-sex-adjusted prevalence was calculated for the mainstream sample using direct standardisation to the street health cohort. $\chi^{2}$ tests were used to examine prevalence differences between the two cohorts. Patterns of multimorbidity are expressed as frequencies.

In addition, to examine age of onset of multimorbidity, we modelled the probability of multimorbidity as a 
function of age. First, a logistic regression analysis was run with the presence of multimorbidity as the dependent variable, and clinic, age and age squared (given the non-linear relationship between age and multimorbidity) as independent variables (IV). The regression coefficients $(\beta)$ for each IV were then used to model the probability of multimorbidity as a function of age in each sample.

Multimorbidity severity was examined using the CIRS SI score as well as distribution of patients within each CIRS severity category. General linear modelling (GLM) was used to examine differences in multimorbidity severity between the two samples, controlling for age and gender. We also counted and compared the number of patients with at least one level 3 or 4 score across CIRS domains,${ }^{20}$ as well as the number of domains with a level 3 or 4 score for each patient as additional indicators of disease severity.

Subgroup analysis was conducted to examine the prevalence and severity of multimorbidity in Indigenous and non-Indigenous patients in the street health cohort. There were no data on Indigenous status in the mainstream cohort for comparison.

We also examined the relationship between demographic characteristics and the presence of multimorbidity across 2, 3 and 5 domains using a series of logistic regression analyses.

Inter-rater reliability between data extractors was assessed using Cronbach's $\alpha$.

\section{RESULTS}

\section{Patient characteristics}

A total of 2587 patients attended the street health service and 4583 attended the mainstream practice over the study periods. The age and gender distribution of patients at both clinics are shown in table 1 . The mean age of street health patients was 37.8 years $(\mathrm{SD}=18.7)$ compared with $36.2(\mathrm{SD}=21.1)$ for the mainstream practice. There were no significant differences in age between the two cohorts, $\mathrm{p}=0.055$, but a significant difference in gender distribution was observed. The majority of the street health patients were men $(57.3 \%, 1482 / 2587)$ while the majority of patients attending the mainstream practice were women (60.7\%, 2783/4583), $\mathrm{p}<0.001$.

Aboriginal patients were $29.6 \%(766 / 2587)$ of the street health sample. On average, Aboriginal patients were significantly younger than non-Aboriginal patients, with $36.8 \%$ (282/766) under the age of 25 compared with only $18.9 \% \quad(344 / 1821)$ of non-Aboriginals, $\mathrm{p}<0.001$. The majority of non-Aboriginal patients were men $(60.2 \%, 1097 / 1821)$ while there was a more even gender distribution for Aboriginal patients attending the street health service (men 50.3\%, 385/766), $\mathrm{p}<0.001$.

\section{Inter-rater reliability}

Inter-rater reliability between data extractors was tested on CIRS scores and number of domains with morbidities for 30 randomly selected patients from each of the two cohorts. For the street health cohort, the intraclass correlation coefficient (ICC) was 0.94 (95\% CI 0.89 to 0.97 ) for number of domains with morbidities and 0.96 (95\% CI 0.93 to 0.98 ) for total CIRS scores indicating high inter-rater reliability. For the mainstream practice sample, the ICC was 0.98 (95\% CI 0.97 to 0.99 ) for number of domains with morbidities and 0.98 (95\% CI 0.97 to 0.99 ) for CIRS scores.

\section{Prevalence of multimorbidity}

Overall, the crude prevalence of multimorbidity was lower in the street health sample. Multimorbidity, based on the presence of conditions affecting $2+$ domains, was present in $46.3 \%$ (1199/2587, $95 \%$ CI $44.4 \%$ to $48.3 \%)$

Table 1 Age and gender distribution for study population

\begin{tabular}{|c|c|c|c|c|}
\hline & \multicolumn{3}{|c|}{ Fremantle Street Doctor } & \multirow{2}{*}{$\begin{array}{l}\text { Mainstream } \\
\text { practice }(n=4583)\end{array}$} \\
\hline & Overall $(n=2587)$ & Aboriginal $(n=766)$ & Non-Aboriginal $(n=1821)$ & \\
\hline \multicolumn{5}{|l|}{ Sex, \% (n) } \\
\hline Male & $57.3(1482)$ & $50.3(385)$ & $60.2(1097)$ & $39.3(1800)$ \\
\hline Female & $42.7(1105)$ & $49.7(381)$ & $39.8(724)$ & 60.7 (2783) \\
\hline \multicolumn{5}{|c|}{ Age, mean (SD) [range] } \\
\hline Overall & $\begin{array}{l}37.8(18.7) \\
{[0-103]}\end{array}$ & $\begin{array}{l}32.09(17.9) \\
{[0-81]}\end{array}$ & $\begin{array}{l}40.19(18.5) \\
{[0-103]}\end{array}$ & $\begin{array}{l}36.18(21.1) \\
{[0-98]}\end{array}$ \\
\hline Male & $\begin{array}{l}39.1(18.5) \\
{[0-103]}\end{array}$ & $\begin{array}{l}31.8(18.1) \\
{[1-81]}\end{array}$ & $\begin{array}{l}41.6(17.9) \\
{[0-103]}\end{array}$ & $\begin{array}{l}35.1(22.3) \\
{[0-92]}\end{array}$ \\
\hline Female & $\begin{array}{l}36.1(18.7) \\
{[0-90]}\end{array}$ & $\begin{array}{l}32.3(17.7) \\
{[0-75]}\end{array}$ & $\begin{array}{l}38.0(18.9) \\
{[0-90]}\end{array}$ & $\begin{array}{l}36.9(20.3) \\
{[0-98]}\end{array}$ \\
\hline \multicolumn{5}{|c|}{ Age category, \% (n) } \\
\hline$<25$ & $24.2(626)$ & $36.8(282)$ & $18.9(344)$ & $28.9(1326)$ \\
\hline $25-44$ & 39.5 (1023) & $35.8(274)$ & $41.1(749)$ & 35.7 (1635) \\
\hline $45-64$ & $28.3(732)$ & $24.4(187)$ & $29.9(545)$ & $27.1(1243)$ \\
\hline $65-74$ & $5.3(136)$ & $2.3(18)$ & $6.5(118)$ & $4.6(211)$ \\
\hline $75+$ & $2.7(70)$ & $0.7(5)$ & $3.6(65)$ & $3.7(168)$ \\
\hline
\end{tabular}


of street health patients, compared with $50.1 \%$ (2294/ $4583,95 \%$ CI $48.6 \%$ to $51.5 \%$ ) of the mainstream sample, $\mathrm{p}=0.003$.

After direct age-sex adjustment of the mainstream prevalence rates, the prevalence of multimorbidity was significantly higher in the street health $(46.3 \%, 1199$ / $2587,95 \%$ CI $44.4 \%$ to $48.3 \%$ ) compared with mainstream sample $(43.1 \%, 2000 / 4583,95 \%$ CI $42.2 \%$ to $45.8 \%), p=0.011$. The prevalence of multimorbidity in $3+$ domains was comparable between the street health (28.0\%, $724 / 2587,95 \%$ CI $26.3 \%$ to $29.7 \%)$ and mainstream samples $(29.2 \%, 1339 / 4583,95 \%$ CI $27.9 \%$ to $30.5 \%), \mathrm{p}=0.269$. There was also no significant difference in multimorbidity prevalence across $5+$ domains between the street health $(10 \%, 259 / 2587,95 \%$ CI $8.9 \%$ to $11.2 \%)$ and mainstream $(10.5 \%, 485 / 4583,95 \%$ CI $9.7 \%$ to $11.5 \%$ ) samples, $\mathrm{p}=0.437$.

Figure 1 shows prevalence of multimorbidity across 2+ domains for the street health and age-sex-adjusted mainstream samples across age groups. The prevalence of multimorbidity among street health patients aged $<45$ years $(37.3 \%, 615 / 1649,95 \%$ CI $34.9 \%$ to $39.7 \%)$ was significantly higher than in the adjusted mainstream sample $(33.0 \%, 977 / 2961,95 \%$ CI $31.3 \%$ to $34.7 \%)$, $\mathrm{p}=0.003$. Multimorbidity prevalence was comparable in the 45-64-year age group for the street health $(62.0 \%$, $454 / 732,95 \%$ CI $58.4 \%$ to $65.5 \%)$ and adjusted mainstream $(62.5 \%, 778 / 1243,95 \%$ CI $59.9 \%$ to $66.2 \%)$ samples, $\mathrm{p}=0.825$. Multimorbidity prevalence was significantly lower in the street health sample for patients $65+$ years $(62.0 \%, 114 / 184,95 \%$ CI $54.8 \%$ to $68.7 \%)$ compared with the adjusted mainstream sample $(90.7 \%$, $322 / 355,95 \%$ CI $87.2 \%$ to $93.3 \%$ ), $\mathrm{p}<0.001$.

Age of onset of multimorbidity was different for the two populations (figure 2). For street health patients, the probability of multimorbidity peaked between 61 and 67 years, $\mathrm{P}\left(\mathrm{E}_{\text {StReEt heAlth }}\right)=0.78$, and then decreased. For mainstream patients, the probability of multimorbidity increased with age, with the greatest probability of multimorbidity observed for individuals aged over 70 years,

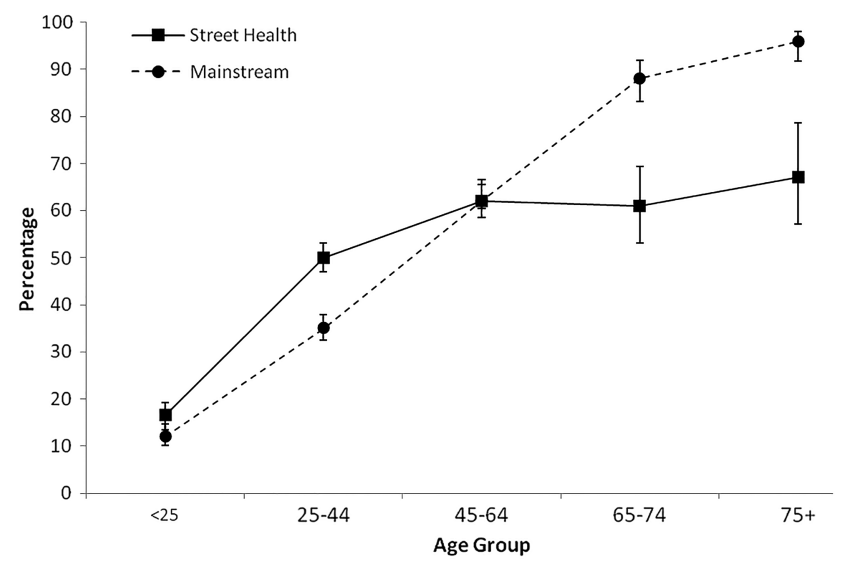

Figure 1 Prevalence of multimorbidity within age groups with $95 \%$ Cls.

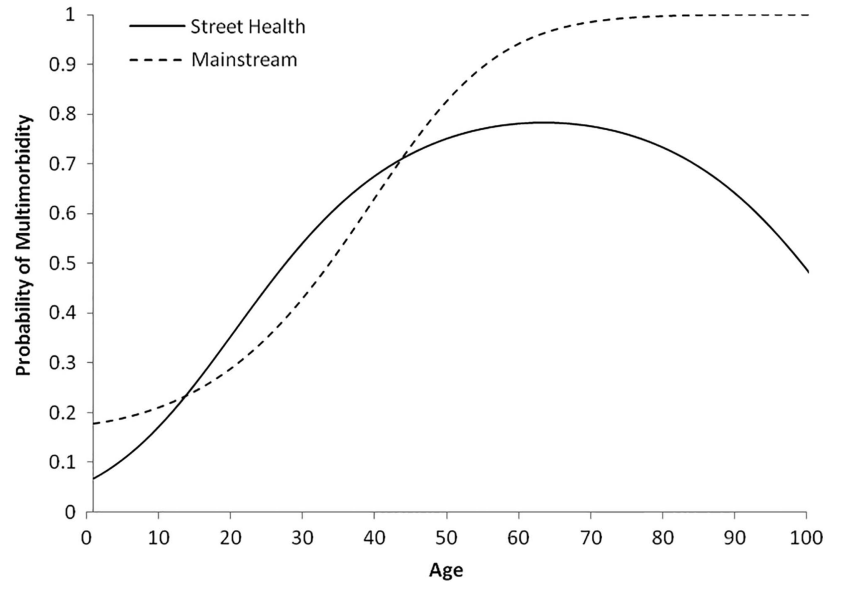

Figure 2 Probability of multimorbidity (2+ domains) as a function of age.

$\mathrm{P}\left(\mathrm{E}_{\text {MAINSTREAM }}\right)=0.99$. Between the ages of 14 and 43 , the probability of multimorbidity was higher for street health patients, $\mathrm{P}\left(\mathrm{E}_{\text {STREET HEALTH }}\right)$ range $0.26-0.71$ versus $\mathrm{P}\left(\mathrm{E}_{\text {MAINSTREAM }}\right)$ range $0.24-0.69$, suggesting that younger street health patients are particularly vulnerable to multimorbidity. The greatest difference was observed between the ages of 23 and 34, $\mathrm{P}\left(\mathrm{E}_{\text {STREeT HEALTH }}\right)$ range $0.43-0.62$ versus $\mathrm{P}\left(\mathrm{E}_{\text {MAINSTREAM }}\right)$ range $0.33-0.52$, with street health patients showing a mean $12 \%$ greater chance of multimorbidity than mainstream patients in this age group.

Overall, for the street health Aboriginal patients, multimorbidity (2+ domains) was present in $50.4 \%$ (386/ $765,95 \%$ CI $46.9 \%$ to $53.9 \%$ ) compared with $44.6 \%$ $(813 / 1821,95 \%$ CI $42.4 \%$ to $46.9 \%)$ in non-Aboriginals, $\mathrm{p}=0.007$. A total of $33.2 \%$ of Aboriginal patients (254/ $766,95 \%$ CI $29.9 \%$ to $36.6 \%$ ) had $3+$ domains affected compared with $25.8 \%(470 / 1821,95 \%$ CI $23.8 \%$ to $27.9 \%$ ) in non-Aboriginals, $\mathrm{p}<0.001$, while $13.7 \%$ (105/ $765,95 \%$ CI $11.5 \%$ to $16.3 \%$ ) had $5+$ domains affected compared with $8.5 \%$ (154/1821, 95\% CI $7.3 \%$ to $9.8 \%)$ in non-Aboriginals, $\mathrm{p}<0.001$. Stratified by age, the prevalence of multimorbidity (2+) across all age groups was significantly higher among Aboriginal compared with non-Aboriginal patients, $\mathrm{p}<0.001$ (figure 3).

\section{Patterns of multimorbidity}

Table 2 displays the prevalence of the five most common body system domain combinations across single, 1+, 2+, 3+ and $5+$ domains for the street health sample with corresponding prevalence rates in mainstream practice for comparison. Table 2 also displays the prevalence of the five most common domain combinations stratified by age.

Table 3 displays the prevalence of the five most common domain combinations across single, 1+, 2+, 3+ and $5+$ domains stratified by Indigenous status and age.

Consistent with the CIRS guidelines, patients with conditions that appeared to be ongoing (eg, chronic ulcers and non-healing skin infections/lacerations) were included in the musculoskeletal/integumental domain. 


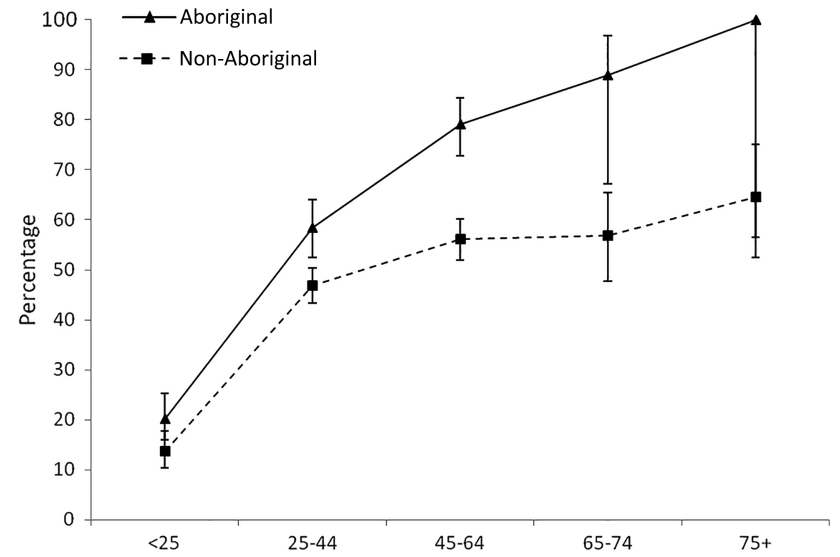

Figure 3 Prevalence of multimorbidity in street health sample stratified by age and Indigenous status with $95 \%$ Cls.

\section{Multimorbidity SI}

Overall, GLM analysis revealed a significantly greater severity of disease among the street health cohort. Controlling for age and gender, street health patients $(\mathrm{M}=1.4$, $\mathrm{SD}=0.91$ ) had significantly higher multimorbidity severity than mainstream patients $(\mathrm{M}=1.1, \mathrm{SD}=0.80), \mathrm{p}<0.001$.

A significantly greater proportion of the street health patients were represented in the moderate $(34.1 \%, 883$ / 2587, $95 \%$ CI $32.3 \%$ to $35.9 \%$ ), $\mathrm{p}<0.001$, and severe categories $(4.9 \%, 126 / 2587,95 \%$ CI $4.1 \%$ to $5.8 \%)$, $\mathrm{p}<0.001$, compared with mainstream patients (moderate: $21.0 \%, 961 / 4583,95 \%$ CI $19.8 \%$ to $22.2 \%$; severe: $1.2 \%$, $53 / 4583,95 \%$ CI $0.9 \%$ to $1.5 \%)$. When multimorbidity severity was stratified by age (figure 4 ), a greater proportion of street health patients were again represented in the moderate and severe categories across every age category.

Overall, $24.4 \%(632 / 2587)$ of street health patients compared with $10.1 \%(463 / 4583)$ of mainstream patients had at least one level 3 or level 4 score across domains, $\mathrm{p}<0.001$. For patients with multimorbidity, this was $44.2 \%$ (530/1199) for the street health cohort versus $18.3 \%$ $(420 / 2294)$ of mainstream patients, $\mathrm{p}<0.001$.

Table 2 Overall and age category breakdown for the five most common domains for street health cohort

\begin{tabular}{|c|c|c|c|c|c|c|c|}
\hline \multirow[b]{2}{*}{ Domains } & \multirow{2}{*}{$\begin{array}{l}\text { Street } \\
\text { health } \\
\% \text { (n) }\end{array}$} & \multirow{2}{*}{$\begin{array}{l}\text { Mainstream } \\
\text { practice \% } \\
\text { (n)ף†‡§ }\end{array}$} & \multicolumn{5}{|c|}{ Age category (street health cohort only) } \\
\hline & & & $<25$ & $25-44$ & $45-64$ & $65-74$ & $75+$ \\
\hline \multicolumn{8}{|l|}{ One domain only $(n=798)$} \\
\hline Musculoskeletal & $29.8(238)^{*}$ & $21.8(231)$ & $24.2(58)$ & $49.2(117)$ & $19.7(47)$ & $5.9(14)$ & $0.8(2)$ \\
\hline Psychiatric & $20.3(162)$ & $18.7(198)$ & $20.4(33)$ & $53.7(87)$ & $24.1(39)$ & $1.9(3)$ & 0 \\
\hline Eye, ear, nose and throat & $13.7(109)^{\star \star}$ & $9.7(103)$ & $62.4(68)$ & $18.3(20)$ & $14.7(16)$ & $0.9(1)$ & $3.7(4)$ \\
\hline Respiratory & $9.4(75)$ & $17.8(188)$ & $38.7(29)$ & $29.3(22)$ & $30.7(23)$ & $1.3(1)$ & 0 \\
\hline Genitourinary & $6.9(55)$ & $8.5(90)$ & $14.5(8)$ & $69.1(38)$ & $14.5(8)$ & $1.8(1)$ & 0 \\
\hline \multicolumn{8}{|l|}{ One or more domains $(n=1997)$} \\
\hline Psychiatric & $46.7(933)^{\star}$ & $34.6(1161)$ & $8.6(80)$ & $48.9(456)$ & $36.5(341)$ & $4.7(44)$ & $1.3(12)$ \\
\hline Musculoskeletal & $42.9(856)$ & $45.2(1514)$ & $13.1(112)$ & $44.6(382)$ & $31.8(272)$ & $7.1(61)$ & $3.4(29)$ \\
\hline Respiratory & $35.0(699)$ & $35.6(1193)$ & $11.7(82)$ & $43.2(302)$ & $38.6(270)$ & $4.9(34)$ & $1.6(11)$ \\
\hline Eye, ear, nose and throat & $19.1(381)^{\star *}$ & $22.7(762)$ & $29.4(112)$ & $29.7(113)$ & $29.7(113)$ & $6.3(24)$ & $5.0(19)$ \\
\hline Vascular & $18.2(364)^{*}$ & $22.3(746)$ & $3.3(12)$ & $17.6(64)$ & $53.8(196)$ & $13.5(49)$ & $11.8(43)$ \\
\hline \multicolumn{8}{|l|}{ Two or more domains $(n=1199)$} \\
\hline Psychiatric+respiratory & $37.1(445)^{\star}$ & $18.8(432)$ & $7.2(32)$ & $48.3(215)$ & $39.1(174)$ & $4.3(19)$ & $1.1(5)$ \\
\hline Psychiatric+musculoskeletal & $32.4(388)^{\star}$ & $22.2(510)$ & $3.6(14)$ & $47.2(183)$ & $41.8(162)$ & $5.7(22)$ & $1.8(7)$ \\
\hline Respiratory+musculoskeletal & $25.6(307)^{\star *}$ & $22.4(515)$ & $5.9(18)$ & $42.3(130)$ & $43.3(133)$ & $6.8(21)$ & $1.6(5)$ \\
\hline Vascular+musculoskeletal & $14.6(175)^{\star}$ & $19.4(445)$ & $2.3(4)$ & $17.7(31)$ & $50.9(89)$ & $15.4(27)$ & $13.7(24)$ \\
\hline Hepatic-pancreatic+psychiatric & $14.3(172)^{\star}$ & $2.8(64)$ & $1.7(3)$ & $45.9(79)$ & $45.9(79)$ & $5.3(9)$ & $1.2(2)$ \\
\hline \multicolumn{8}{|l|}{ Three or more domains $(n=724)$} \\
\hline $\begin{array}{l}\text { Psychiatric+respiratory+ } \\
\text { musculoskeletal }\end{array}$ & $30.9(224)^{\star}$ & $14.7(215)$ & $3.6(8)$ & $42.4(95)$ & $47.3(106)$ & $5.8(13)$ & $0.9(2)$ \\
\hline $\begin{array}{l}\text { Psychiatric+haematological+ } \\
\text { endocrine }\end{array}$ & $14.5(105)$ & $14.1(206)$ & $3.8(4)$ & $37.1(39)$ & $46.7(49)$ & $8.6(9)$ & $3.8(4)$ \\
\hline Psychiatric+respiratory+vascular & $14.4(104)^{\star}$ & $8.5(125)$ & $2.9(3)$ & $25.0(26)$ & $60.6(63)$ & $8.7(9)$ & $2.9(3)$ \\
\hline $\begin{array}{l}\text { Psychiatric+musculoskeletal+ } \\
\text { vascular }\end{array}$ & $14.2(103)$ & $13.1(192)$ & $1.0(1)$ & $18.4(19)$ & $60.2(62)$ & $14.6(15)$ & $5.8(6)$ \\
\hline $\begin{array}{l}\text { Psychiatric+respiratory+lower } \\
\text { gastrointestinal }\end{array}$ & $13.8(100)^{\star}$ & $5.9(87)$ & $1.0(1)$ & $46.0(46)$ & $50.0(50)$ & $1.0(1)$ & $2.0(2)$ \\
\hline \multicolumn{8}{|c|}{ 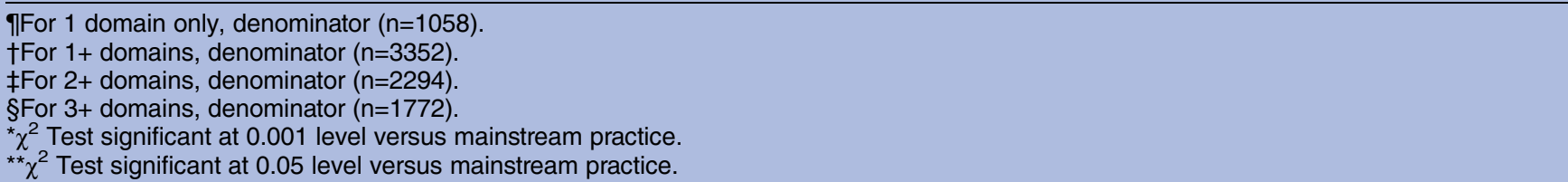 } \\
\hline
\end{tabular}


Table 3 Overall and age category breakdown for the five most common domains for Aboriginal street health patients

\begin{tabular}{|c|c|c|c|c|c|c|c|}
\hline \multirow[b]{2}{*}{ Domains } & \multirow{2}{*}{$\begin{array}{l}\text { Aboriginal } \\
\%(n)\end{array}$} & \multirow{2}{*}{$\begin{array}{l}\text { Non-Aboriginal } \\
\%(n) \eta \dagger \ddagger \S\end{array}$} & \multicolumn{5}{|c|}{ Age category (Aboriginal patients only) } \\
\hline & & & $<25$ & $25-44$ & $45-64$ & $65-74$ & $75+$ \\
\hline \multicolumn{8}{|l|}{ One domain only $(n=216)$} \\
\hline Musculoskeletal & $34.3(74)$ & $28.2(164)$ & $55.4(41)$ & $36.5(27)$ & $8.1(6)$ & 0 & 0 \\
\hline Eye, ear, nose and throat & $19.0(41)^{*}$ & $11.7(68)$ & $85.4(35)$ & $12.2(5)$ & $2.4(1)$ & 0 & 0 \\
\hline Psychiatric & $13.0(28)^{*}$ & $23.0(134)$ & $25.0(7)$ & $57.1(16)$ & $17.9(5)$ & 0 & 0 \\
\hline Respiratory & $8.3(18)$ & $9.8(57)$ & $55.6(10)$ & $22.2(4)$ & $22.2(4)$ & 0 & 0 \\
\hline Lower gastrointestinal & $6.0(13)$ & $5.0(29)$ & $30.8(4)$ & $53.8(7)$ & $15.4(2)$ & 0 & 0 \\
\hline \multicolumn{8}{|l|}{ One or more domains $(n=602)$} \\
\hline Musculoskeletal & $47.5(286)^{\star}$ & $40.9(570)$ & $25.9(74)$ & $40.2(115)$ & $30.1(86)$ & $3.1(9)$ & $0.7(2)$ \\
\hline Psychiatric & $45.5(274)$ & $47.2(659)$ & $10.6(29)$ & $47.8(131)$ & $37.2(102)$ & $4.0(11)$ & $0.4(1)$ \\
\hline Respiratory & $38.7(233)^{\star}$ & $33.4(466)$ & $16.3(38)$ & $42.5(99)$ & $36.9(86)$ & $3.4(8)$ & $0.9(2)$ \\
\hline Eye, ear, nose and throat & $24.9(150)^{\star *}$ & $16.6(231)$ & $42.0(63)$ & $27.3(41)$ & $24.7(37)$ & $4.0(6)$ & $2.0(3)$ \\
\hline Endocrine & $24.4(147)^{\star \star}$ & $13.3(186)$ & $7.5(11)$ & $34.0(50)$ & 46.9 (69) & $8.8(13)$ & $2.7(4)$ \\
\hline \multicolumn{8}{|l|}{ Two or more domains $(n=386)$} \\
\hline Psychiatric+respiratory & 39.6 (153) & 35.9 (292) & $9.8(15)$ & $47.7(73)$ & $38.6(59)$ & $3.3(5)$ & $0.7(1)$ \\
\hline Psychiatric+musculoskeletal & $35.2(136)$ & $31.0(252)$ & $5.1(7)$ & $46.3(63)$ & $44.1(60)$ & $4.4(6)$ & 0 \\
\hline Respiratory+musculoskeletal & $31.3(121)^{\star}$ & $22.9(186)$ & $9.1(11)$ & $42.1(51)$ & $43.8(53)$ & $4.1(5)$ & $0.8(1)$ \\
\hline Respiratory+endocrine & $20.2(78)^{\star \star}$ & $7.7(63)$ & $5.1(4)$ & $35.9(28)$ & $50.0(39)$ & $7.7(6)$ & $1.3(1)$ \\
\hline Psychiatric+endocrine & $19.2(74)^{\star *}$ & $10.2(83)$ & $5.4(4)$ & $36.5(27)$ & $47.3(35)$ & $9.5(7)$ & $1.4(1)$ \\
\hline \multicolumn{8}{|l|}{ Three or more domains $(n=254)$} \\
\hline $\begin{array}{l}\text { Psychiatric+respiratory+ } \\
\text { musculoskeletal }\end{array}$ & $35.8(91)^{*}$ & $28.3(133)$ & $5.5(5)$ & $44.0(40)$ & $47.3(43)$ & $3.3(3)$ & 0 \\
\hline $\begin{array}{l}\text { Psychiatric+haematological+ } \\
\text { endocrine }\end{array}$ & $22.4(57)^{\star \star}$ & $10.2(48)$ & $3.5(2)$ & $40.4(23)$ & $47.4(27)$ & $7.0(4)$ & $1.8(1)$ \\
\hline $\begin{array}{l}\text { Respiratory+musculoskeletal+ } \\
\text { endocrine }\end{array}$ & $18.9(48)^{\star \star}$ & $7.4(35)$ & $2.1(1)$ & $31.3(15)$ & $60.4(29)$ & $6.3(3)$ & 0 \\
\hline Vascular+respiratory+endocrine & $18.5(47)^{\star \star}$ & $6.8(32)$ & 0 & $27.7(13)$ & $63.8(30)$ & $6.4(3)$ & $2.1(1)$ \\
\hline Psychiatric+vascular+respiratory & $18.1(46)^{\star}$ & $12.3(58)$ & $2.2(1)$ & $28.3(13)$ & $65.2(30)$ & $2.2(1)$ & $2.2(1)$ \\
\hline \multicolumn{8}{|c|}{$\begin{array}{l}\text { IFFor } 1 \text { domain only, denominator }(n=582) . \\
\text { †For } 1+\text { domains, denominator }(n=1395) . \\
\text { †For } 2+\text { domains, denominator }(n=813) . \\
\text { §For } 3+\text { domains, denominator }(n=470) . \\
{ }^{*} \chi^{2} \text { Test significant at } 0.05 \text { level versus non-Aboriginal. } \\
{ }^{* \star} \chi^{2} \text { Test significant at } 0.001 \text { level versus non-Aboriginal. }\end{array}$} \\
\hline
\end{tabular}

Figure 5 shows the frequency trends of number of domains with level 3 or 4 scores $^{20}$ for patients with multimorbidity across 2+ domains for both cohorts, revealing a more pronounced and earlier onset of increased disease burden in the 25-44 and 45-64-year age group for street health patients, but especially Aboriginal patients.

For the street health cohort, Aboriginal patients scored marginally higher on the CIRS SI $(\mathrm{M}=1.39$, $\mathrm{SD}=0.89$ ) compared with non-Aboriginal patients $(\mathrm{M}=1.34, \mathrm{SD}=0.91)$, although this difference was not statistically significant, $\mathrm{p}=0.610$.

\section{Factors associated with multimorbidity}

Logistic regression analyses using the occurrence of multimorbidity across 2+, 3+ and 5+ domains as the criterion variable showed multimorbidity to be significantly associated with male gender, increasing age and Indigenous status (table 4). Indigenous status was the strongest predictor of multimorbidity in each model. Aboriginal patients had an $87 \%$ increase in the likelihood of displaying multimorbidity across $2+$ domains compared with non-Aboriginals. Aboriginal patients were also twice as likely to show multimorbidity across 3+domains and nearly three times more likely to show multimorbidity across 5+ domains.

\section{DISCUSSION}

Research on multimorbidity among street health populations is scarce with little data available on patterns, prevalence or disease severity among particular age or ethnic groups. Existing research has tended to focus on specific areas, such as homelessness and mental health, ${ }^{27-29}$ with little attention paid to the cumulative and synergistic effects of multiple chronic conditions or a broader biopsychosocial approach to healthcare needs. ${ }^{40}$ The prevalence of multimorbidity is higher in deprived as opposed to more affluent areas ${ }^{31}$ with multiple physical diseases often coexisting among patients with mental illness. 43132

This is the first study to use 42 conditions affecting anatomical domains to estimate patterns and prevalence of multimorbidity among marginalised and homeless 


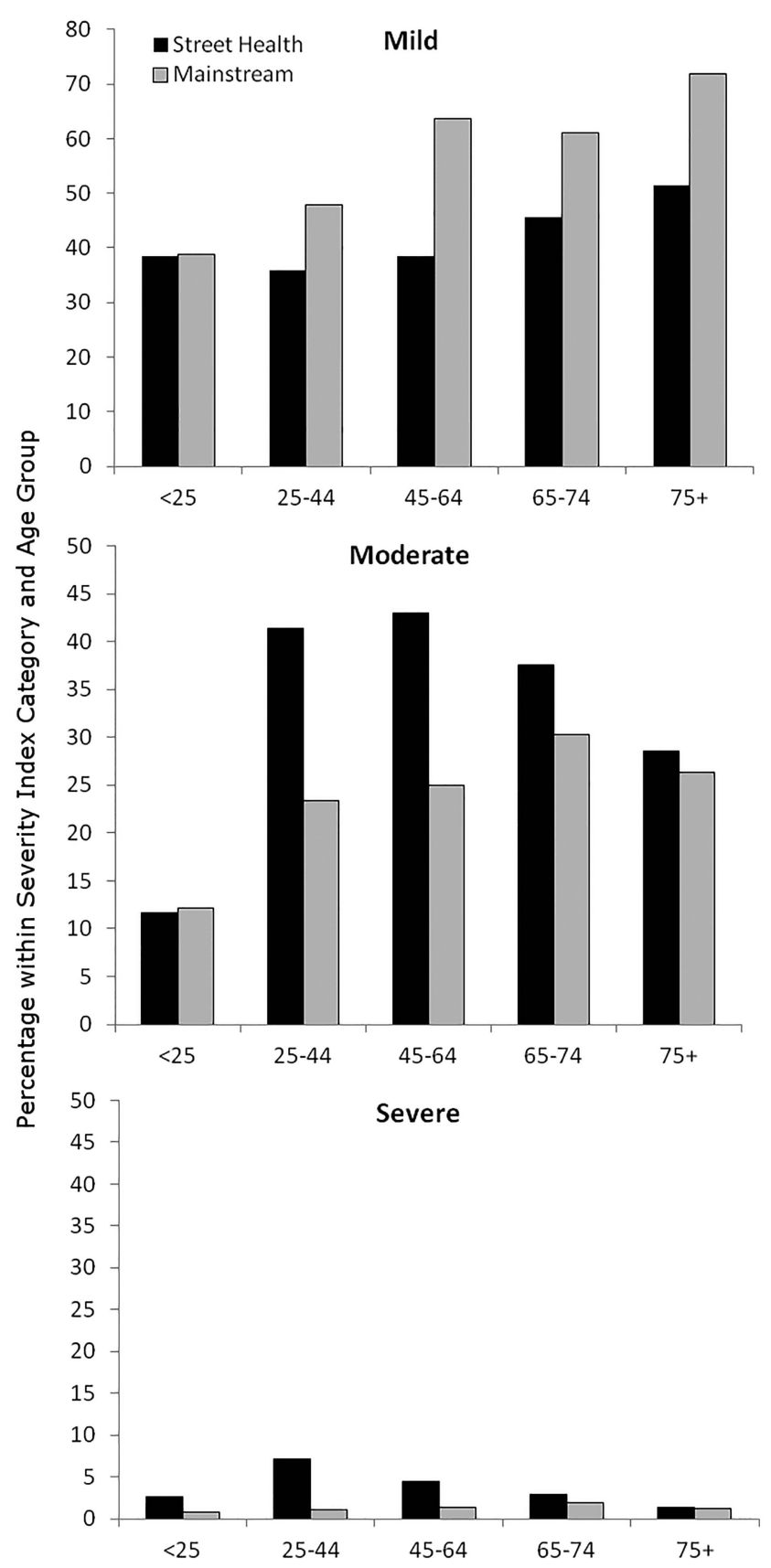

Figure 4 Severity Index distribution within age groups.

patients attending a designated, primary care-run, streetbased outreach service. Like our earlier mainstream practices study, ${ }^{24}$ we include an estimation of disease severity to enhance the overall picture of multimorbidity burden in this population.

Key findings from our study include that multimorbidity is significantly associated with male gender, increasing age and Indigenous status, with the latter the strongest predictor of multimorbidity irrespective of whether 2+, $3+$ or $5+$ domains are used as the criterion variable.

\section{Strengths and limitations of the study}

The strengths of this study include the large street health cohort size involving the total population seen over a 6-year period and the fact that we include a disease severity rating for each patient in addition to prevalence and patterns data recorded.

A major difficulty we encountered was enumerating the homeless population mainly because it lacked a common definition. ${ }^{33}$ The open access policy to the street health service could have had a diluting effect on the proportion of more traditional users of the service because of one-off opportunistic and convenience attendances. Among street health patients, $22.8 \%$ had no multimorbidity compared with $26.9 \%$ among mainstream patients.

Our method of estimation of multimorbidity relies on the accrual of formal diagnoses of conditions, which in turn partly relies on regular attendance with care providers. Hence, the transient nature of the street health cohort may have impact on the estimation of multimorbidity compared with the more stable mainstream cohort.

In addition, while the street health population is based on attendances over a 6-year period, the comparator mainstream practice data are based on attendances over over 6 months. ${ }^{24}$

Chronic skin ulcers and slow to heal lacerations/infections were prominent in the street cohort compared with mainstream, reflecting the reality of the street cohort population's poor living circumstances and hygiene. Inclusion of these conditions as part of the musculoskeletal/integumental domain was based on their recurrent, chronic presentations in this population and is likely to have increased the overall prevalence of this domain. It was not possible to estimate the proportion of the musculoskeletal/integumental domain that related to chronic skin problems.

\section{Prevalence and patterns}

Multimorbidity prevalence among the street health cohort was significantly higher than the age-sex-adjusted prevalence for the mainstream cohort. The age breakdown across 2+ domains shows younger patients as much more vulnerable to having multiple chronic conditions with a $12 \%$ greater likelihood among 23-34-year-old patients. This contrasts with findings from our earlier research where prevalence patterns progressively increased from the 25-44-year age group to the 45-64 and 65-74-year age groups ${ }^{24}$ and results in the flatter trajectory of the S-shaped distribution curve as seen in figure 1 . The reason for multimorbidity peaking in the 25-44-year age group in the street health population could be explained by the premature deaths of these patients or the possibility that those surviving to older age start attending mainstream practices or become institutional residents.

A key finding from our study is the willingness of Aboriginal patients to attend the street health service$29.6 \%$ vs $1.6 \%$ to Australian primary care practices ${ }^{34}$ and that Aboriginal patients overall are significantly younger-36.8\% vs $18.9 \%$ under 25 years old-than 
Figure 5 Frequency trends of number of domains with level 3 or 4 scores.

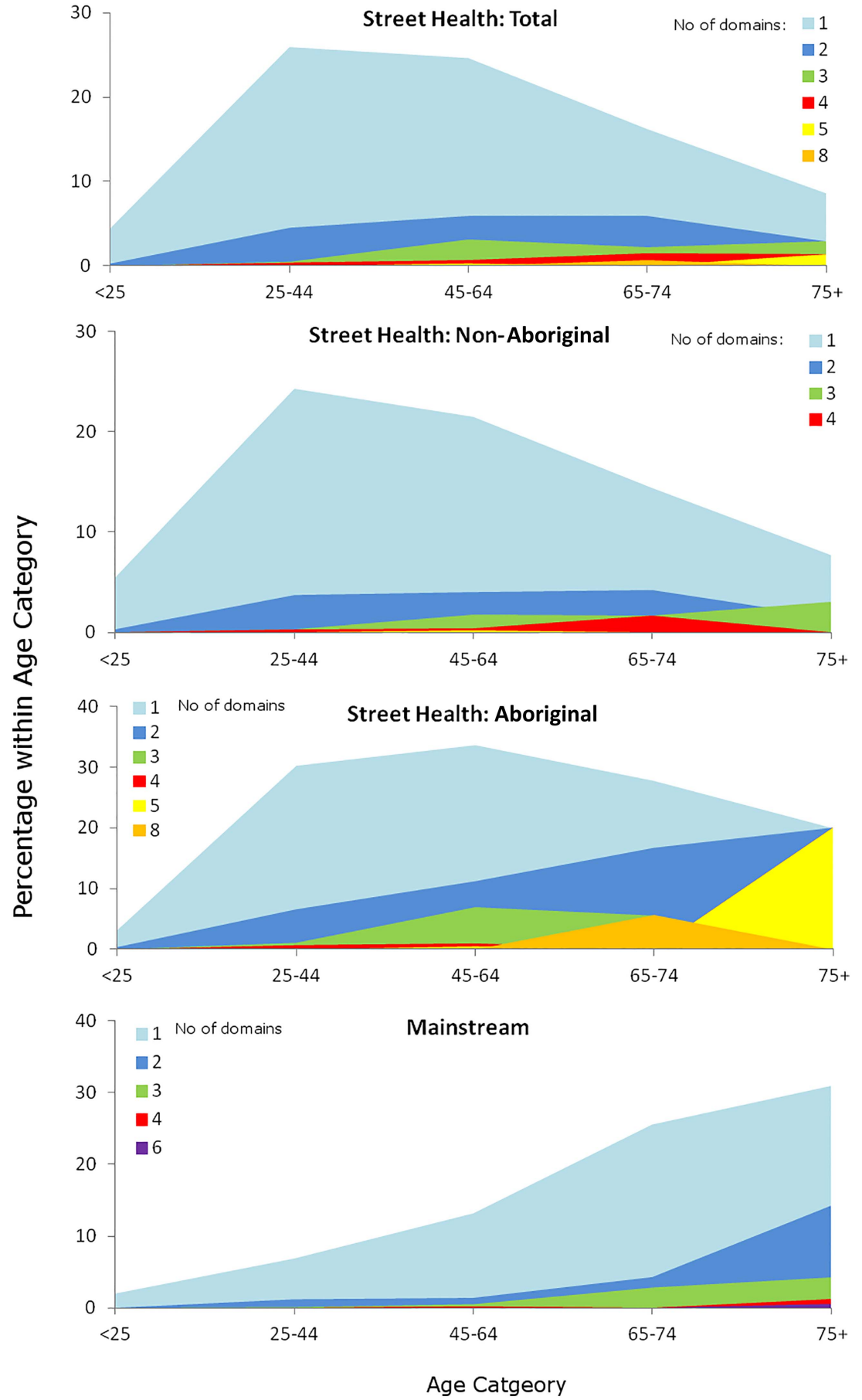

Age Catgeory
non-Aboriginal patients. Owing to a lack of data on Indigenous status among the mainstream practice, it was not possible to compare both cohorts. Among the street health population, Aboriginal patients have significantly higher rates of multimorbidity across all age groups and number of domains affected.

The high prevalence of psychiatric morbidity $(46.7 \%)$ was not unexpected. The three most common domains — psychiatric, musculoskeletal $(42.9 \%)$ and respiratory $(35.0 \%)$-are similar to mainstream except that psychiatry and musculoskeletal are juxtaposed. ${ }^{24}$ These three domains remain most common even when $2+$ or $3+$ domains are examined and may act to facilitate or accelerate other morbidities resulting in premature ageing or progressive deterioration.

The possibility that early onset of psychiatric illness may in turn contribute to a cascade of homelessness, lack of stable relationships and failure to achieve educational potential should be considered.

\section{Disease severity}

Disease severity burden is of particular value in disadvantaged populations because the cumulative and synergistic nature of their multimorbidities impacts on their need for appropriate health services, ${ }^{30}$ while their socioeconomic circumstances renders their access to such 
Table 4 Relation between sociodemographic characteristics and the prevalence of multimorbidity

\begin{tabular}{|c|c|c|}
\hline Characteristic & OR & $95 \% \mathrm{Cl}$ \\
\hline \multicolumn{3}{|l|}{ 2+ Domains } \\
\hline Male* & 1.44 & 1.22 to 1.70 \\
\hline $\mathrm{Age}^{*}$ & 1.01 & 1.04 to 1.05 \\
\hline Indigenous* & 1.87 & 1.55 to 2.26 \\
\hline \multicolumn{3}{|l|}{ 3+ Domains } \\
\hline Male* & 1.41 & 1.17 to 1.70 \\
\hline $\mathrm{Age}^{*}$ & 1.04 & 1.04 to 1.05 \\
\hline Indigenous* & 2.17 & 2.17 to 2.66 \\
\hline \multicolumn{3}{|l|}{ 5+ Domains } \\
\hline Male $^{*}$ & 1.26 & 0.96 to 1.67 \\
\hline $\mathrm{Age}^{\star}$ & 1.05 & 1.04 to 1.06 \\
\hline Indigenous* & 2.82 & 2.11 to 3.77 \\
\hline
\end{tabular}

services inequitable. American, ${ }^{10}$ Canadian $^{9}$ and British $^{12}{ }^{13}$ studies have all found much common ground with housing, mental illness, poor education and smoking common factors throughout. Complex interventions invariably do better when housing is integrated into the solution and the importance of social geography and family supports acknowledged. ${ }^{7}$ There is no definitive answer but well-integrated support networks built around primary care services would appear a logical way forward.

We found the multimorbidity SI significantly higher for street health patients, more pronounced with 'moderate' and 'severe' morbidity and persisting across all age categories. Given the large numbers in the two population cohorts, the relatively small but significant differences of $13 \%$ in the moderately severe and $4 \%$ in the severe disease SI categories translate to a substantial number of patients. The impost in terms of service delivery could therefore be greater than is primarily evident. Taken together with the fact that the presence of multiple severe or moderately severe chronic conditions is not compatible with long-term survival or management in the primary care setting, especially among a marginalised, street health population, it is likely to impact directly on emergency department visits and hospital admissions.

After age-sex adjustment, multimorbidity prevalence is significantly higher among the street health cohort. Where disease exists, it tends to be of significantly greater severity as reflected by the more pronounced domain levels 3 and 4 scores. This supports earlier research by Starfield and Kinder ${ }^{35}$ that morbidities are not randomly distributed among populations. Instead, those with the highest vulnerability to illness have a greater disadvantage because the clustering of morbidities in these subpopulations diminishes their quality of life. ${ }^{3}$ Multimorbidity in such circumstances impacts negatively not just on their functioning status ${ }^{36} 37$ but also causes increased and poorly coordinated use of health services, ${ }^{5}$ increased direct and indirect healthcare $\operatorname{costs}^{6}$ and heightens the risk of premature death. ${ }^{38} 39$

\section{CONCLUSION}

Our study reports on the prevalence, patterns and disease severity of multimorbidity among a marginalised population attending a primary care-led, street health clinic in Western Australia. Overall, the probability of early onset (23-34 years) multimorbidity is higher in the street health cohort compared with mainstream practice but not in patients aged over 45 years, with psychiatric, musculoskeletal and respiratory the commonest domains affected. For Aboriginal patients, the prevalence of multimorbidity is higher across all ages but especially if aged $<25$ years.

Disease severity is significantly higher in the street health population, especially Aboriginal patients, with greater 'moderate' and 'severe' morbidity and persists across all age categories. Attendance patterns for Aboriginal patients suggest they are more likely to engage with street-based, outreach service than mainstream practice. Reasons for this increased engagement warrant further investigation.

Our findings have implications on the design and delivery of healthcare services to meet the increasing challenge of multimorbidity ${ }^{40}$ in disadvantaged and Indigenous populations. Traditional approaches to service delivery fail to meet the needs of this population. ${ }^{12}$ Such services need more complex interventions but are unlikely to receive appropriate health services expenditure and compare unfavourably with the services offered to mainstream patients. A more integrated outreach approach involving better housing, and psychiatric, educational and social supports would seem logical to address their needs. Longer term prospective studies including an economic analysis component would be helpful.

\section{Author affiliations}

${ }^{1}$ General Practice and Primary Health Care Research, School of Medicine, The University of Notre Dame Australia, Fremantle, Western Australia, Australia

${ }^{2}$ Centre for Health Services Research, School of Population Health, University of Western Australia, Crawley, Western Australia, Australia

${ }^{3}$ Institute for Health Research, The University of Notre Dame, Fremantle, Western Australia, Australia

${ }^{4}$ Illawarra Shoalhaven Local Health District, Woolongong, New South Wales, Australia

${ }^{5}$ School of Medicine, The University of Notre Dame Australia, Fremantle, Western Australia, Australia

Acknowledgements The authors acknowledge the assistance of the staff at the Freo Street Doctor clinic, Fremantle Medicare Local and the medical practice involved in the study. They also acknowledge the assistance of Dr Maeve Kiely and Dr Cam Phan with data acquisition. And also acknowledge financial support from J Galvin, W Cunningham, L Ryan and A Neale.

Contributors TB and DEA-R made substantial contributions to the conception and design of the work as well as the acquisition, analysis and interpretation of data for the study. LT and MKB made substantial contributions to the analysis and interpretation of data. RGM made substantial contributions to the acquisition of data. TB, DEA-R and LT were responsible for drafting the 
manuscript and all authors revised it critically for important intellectual content, final approval of the version to be published and agree to be accountable for all aspects of the work in ensuring that questions related to the accuracy or integrity of any part of the work are appropriately investigated and resolved.

Funding Research support was received from the Australian Commonwealth Government Primary Health Care Research Evaluation and Development (PHCRED) Strategy Phase 2. The General Practice and Primary Health Care Research Unit is partly funded under the Collaborative Research Network (CRN) Program Grant from the Australian Government Department of Education to the University of Notre Dame Australia.

Competing interests TB, DEA-R, LT and RGM have received research grant funding. DEA-R has received support from research donations.

Ethics approval Ethics approval for the study was obtained from The University of Notre Dame Australia Human Research Ethics Committee.

Provenance and peer review Not commissioned; externally peer reviewed.

Data sharing statement No additional data are available.

Open Access This is an Open Access article distributed in accordance with the Creative Commons Attribution Non Commercial (CC BY-NC 4.0) license, which permits others to distribute, remix, adapt, build upon this work noncommercially, and license their derivative works on different terms, provided the original work is properly cited and the use is non-commercial. See: http:// creativecommons.org/licenses/by-nc/4.0/

\section{REFERENCES}

1. Barnett K, Mercer SW, Norbury M, et al. Epidemiology of multimorbidity and implications for health care, research, and medical education: a cross-sectional study. Lancet 2012;380:37-43.

2. Fortin M, Lapointe L, Hudon C, et al. Multimorbidity and quality of life in primary care: a systematic review. Health Qual Life Outcomes 2004;2:51.

3. Mercer S, Watt $\mathrm{G}$. The inverse care law: clinical primary care encounters in deprived and affluent areas of Scotland. Ann Fam Med 2007;5:503-10.

4. Payne R, Gray A, Guthrie B, et al. The effect of physical multimorbidity, mental health conditions and socioeconomic deprivation on unplanned admissions to hospital: a retrospective cohort study. CMAJ 2013;185:E221-8

5. Salisbury C, Johnson L, Purdy S, et al. Epidemiology and impact of multimorbidity in primary care: a retrospective cohort study. $\mathrm{Br} J$ Gen Pract 2011;61:18-24.

6. Hoffman C, Rice D, Hai-Yen S. Persons with chronic conditionstheir prevalence and costs. JAMA 1996;276:1473-9.

7. Sadowski L, Kee R, VanderWeele T, et al. Effect of a housing and case management program on emergency department visits and hospitalizations among chronically ill homeless adults. JAMA 2009;301:1771-8

8. Glynn L, Valderas JM, Healy P, et al. The prevalence of multimorbidity in primary care and its effect on health care utilisation and cost. Fam Pract 2011;28:516-23.

9. Hwang S, Wilkins R, Tjepkema M, et al. Mortality among residents of shelters, rooming houses, and hotels in Canada: 11 year follow-up study. BMJ 2009;339:b4036.

10. Lantz P, House J, Lepkowski J, et al. Socioeconomic factors, health behaviors, and mortality: results from a nationally representative prospective study of US adults. JAMA 1998;279:1703-8.

11. Tudor-Hart J. The inverse care law. Lancet 1971:1:405-12.

12. Fazel S, Khosla V, Doll H, et al. The prevalence of mental disorders among the homeless in western countries: systematic review and meta-regression analysis. PLoS Med 2008;5:e225.

13. Shaw M, Dorling D, Brimdlecombe N. Life chances in Britain by housing wealth and for the homeless and vulnerably housed. Environ Plann A 1999;31:2239-48.

14. Riley A, Harding $\mathrm{G}$, Underwood $M$, et al. Homelessness: a problem for primary care? Br J Gen Pract 2003;55:474-9.

15. Gunn JM, Ayton DR, Densley K, et al. The association between chronic illness, multimorbidity and depressive symptoms in an
Australian primary care cohort. Soc Psychiatry Psychiatr Epidemiol 2012;47:175-84.

16. Bloch G, Rozmovits L, Giambrone B. Barriers to primary care responsiveness to poverty as a risk factor for health. BMC Fam Pract 2011;12:62

17. Gelberg L, Gallagher T, Andersen R, et al. Competing priorities as a barrier to medical care among homeless adults in Los Angeles. Am J Public Health 1997;87:217-20.

18. Jeal N, Salisbury C. Self reported experiences of health services among female street-based prostitutes: a cross sectional survey. $\mathrm{Br}$ J Gen Pract 2004;54:215-19.

19. Cummings M, Kang M. Youth health services-improving access to primary care. Aust Fam Physician 2012;41:339-41.

20. Miller MD, Paradis CF, Houck PR, et al. Rating chronic medical illness burden in geropsychiatric practice and research: application of the Cumulative IIIness Rating Scale. Psychiatr Res 1992;41:237-48.

21. Murray S, Skull S. Hurdles to health: immigrant and refugee health care in Australia. Aust Health Rev 2005;29:25-9.

22. Parslow $\mathrm{R}$, Jorm $\mathrm{A}$, Christensen $\mathrm{H}$, et al. Factors associated with young adults obtaining general practitioner services. Aust Health Rev 2002;25:109-17.

23. Shadmi E. Multimorbidity and equity in health. Int $J$ Equity Health 2013;12:59

24. Brett T, Arnold-Reed D, Popescu A, et al. Multimorbidity in patients attending 2 Australian primary care practices. Ann Fam Med 2013;11:535-42.

25. Hudon $\mathrm{C}$, Fortin M, Soubhi $\mathrm{H}$. Abbreviated guidelines for scoring Cumulative IIIness Rating Scale (CIRS) in family practice. J Clin Epidemiol 2007;60:212.

26. O'Halloran J, Miller G, Britt $H$. Definining chronic conditions for primary care with ICPC-2. Fam Pract 2004;21:381-6.

27. Hermann $\mathrm{H}$, Evert $\mathrm{H}$, Harvey $\mathrm{C}$, et al. Disability and service use among homeless people living with psychotic disorders. Aust N Z J Psychiatry 2004;38:965-74.

28. Teesson M, Hodder T, Buhrich N. Psychiatric disorders in homeless men and women in inner Sydney. Aust N Z J Psychiatry 2004;38:162-8.

29. Trevena L, Nutbeam D, Simpson J. Asking the right questions of disadvantaged and homeless communities: the role of housing, patterns of illness and reporting behaviours in the measurement of health status. Aust N Z J Public Health 2001;25:298-304.

30. Bayliss E, Ellis J, Steiner J. Seniors' self-reported multimorbidity captured biopsychosocial factors not incorporated into two other data-based morbidity measures. J Clin Epidemiol 2009;62:550-7.

31. Orueta J, Nuno-Solinis R, Garcia-Alvarez A, et al. Prevalance of multimorbidity according to the deprivation level among the elderly in the Basque Country. BMC Public Health 2013;13:918.

32. Andrade L, Bensenor I, Viana M, et al. Clustering of psychiatric and somatic illnesses in the general population: multimorbidity and socioeconomic correlates. Braz J Med 2010;43:483-91.

33. Fitzpatrick-Lewis D, Ganann R, Krisnaratne S, et al. Effectiveness of interventions to improve the health and housing status of homeless people: a rapid systematic review. BMC Public Health 2011;11:638.

34. Britt H, Miller G, Charles J, et al. A decade of Australian general practice activity 2002-03 to 2011-12. General practice series. Sydney: Sydney University Press, 2012.

35. Starfield B, Kinder K. Multimorbidity and its measurement. Health Policy 2011;103:3-8

36. Bayliss E, Bayliss M, Ware J, et al. Predicting declines in physical function in persons with multiple chronic conditions: what we can learn from the medical problem list. Health Qual Life Outcomes 2004;2:47-51.

37. Lawson K, Mercer S, Wyke S, et al. Double trouble: the impact of multimorbidity and deprivation on preference-weighted health related quality of life - a cross-sectional analysis of the Scottish Health Survey. Int J Equity Health 2013;12:67.

38. Gijsen R, Hoeymans N, Schellevis F, et al. Causes and consequences of comorbidity: a review. J Clin Epidemiol 2001;54:661-74.

39. Yancik R, Wesley M, Ries L, et al. Comorbidity and age as predictors of risk for early mortality of male and female colon carcinoma patients: a population based study. Cancer 1998:82:2123-34.

40. Tinetti M, Fried T, Boyd C. Designing health care for the most common chronic condition-multimorbidity. JAMA 2012:2493-4. 